\title{
The 3rd ERS Lung Science Conference and the future
}

W. MacNee

Respiratory Medicine ELEGI Edinburgh UK

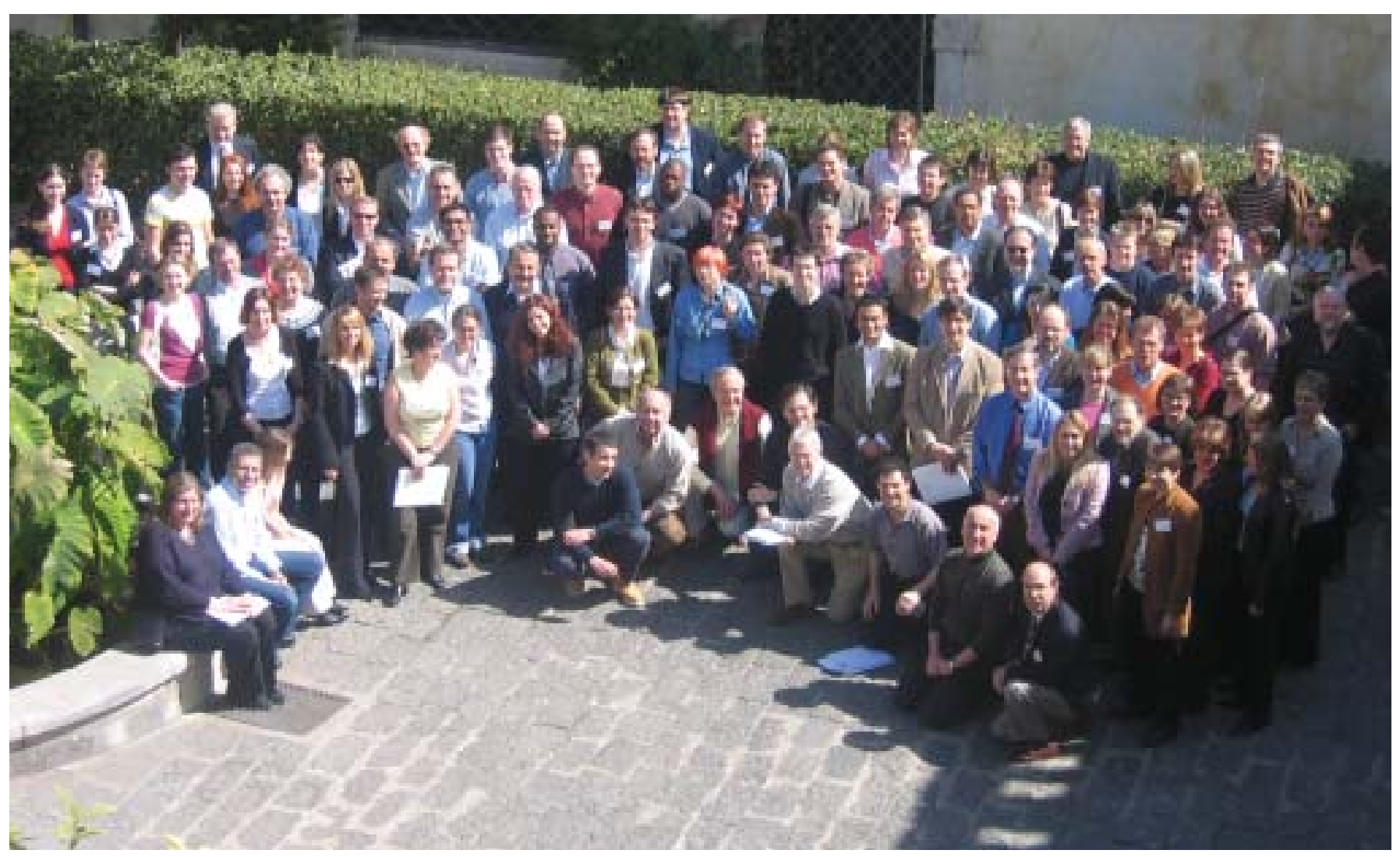

The third in a series of European Respiratory

Science Conferences was held in Taormina, Sicily, at the end of March 2005. The successful format of the previous conferences, with state of the art lectures from internationally renowned scientists mixed with new science presented by young clinical and non-clinical scientists, with much time for discussion, again proved to be highly successful.

This year was the last in the series of three conferences on lung inflammation, with an emphasis on present and future therapeutic interventions in lung inflammatory disorders.
On the theme of intervening in lung inflammation, there were presentations on targeting protease/antiprotease and oxidant/antioxidant imbalance, and lung repair, cytokines, anti-TNF strategies in lung disease and interventions to alter transcriptional factors. These excellent presentations on interventions in lung inflammation were interspersed with other presentations on the pathogenesis of lung fibrosis, apoptosis and lung inflammation, and on new molecular technologies, such as interference RNAs. There was a fascinating talk on gene ontology, how to make sense of gene chip data, and some futuristic 


\title{
Ourth ERS Lung Science Conference
}

\author{
Taormina \\ Sicily, Italy \\ March 24-26, 2006
}

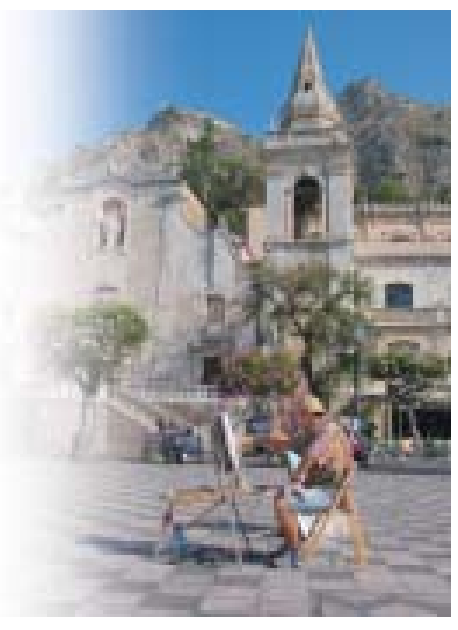

\section{Hypoxia in lung biology and disease}

Conference chairs: W. Seeger and M. Gassmann

Topics:

* Basic mechanisms of hypoxia-sensing and oxygen-dependent signalling

* Oxygen-sensing and control of ventilation

* Acute lung vascular responses to hypoxia

* Hypoxia in sleep-related disorders

Abstract submission deadline: October 3, 2005 Registration deadline: February 15, 2006*

*registration is limited to 150 people and priority will be given to delegates with accepted abstracts

www.ersnet.org/lsc06

E-mail: info@ersnet.org

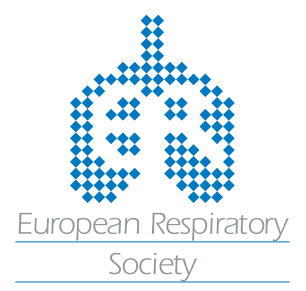



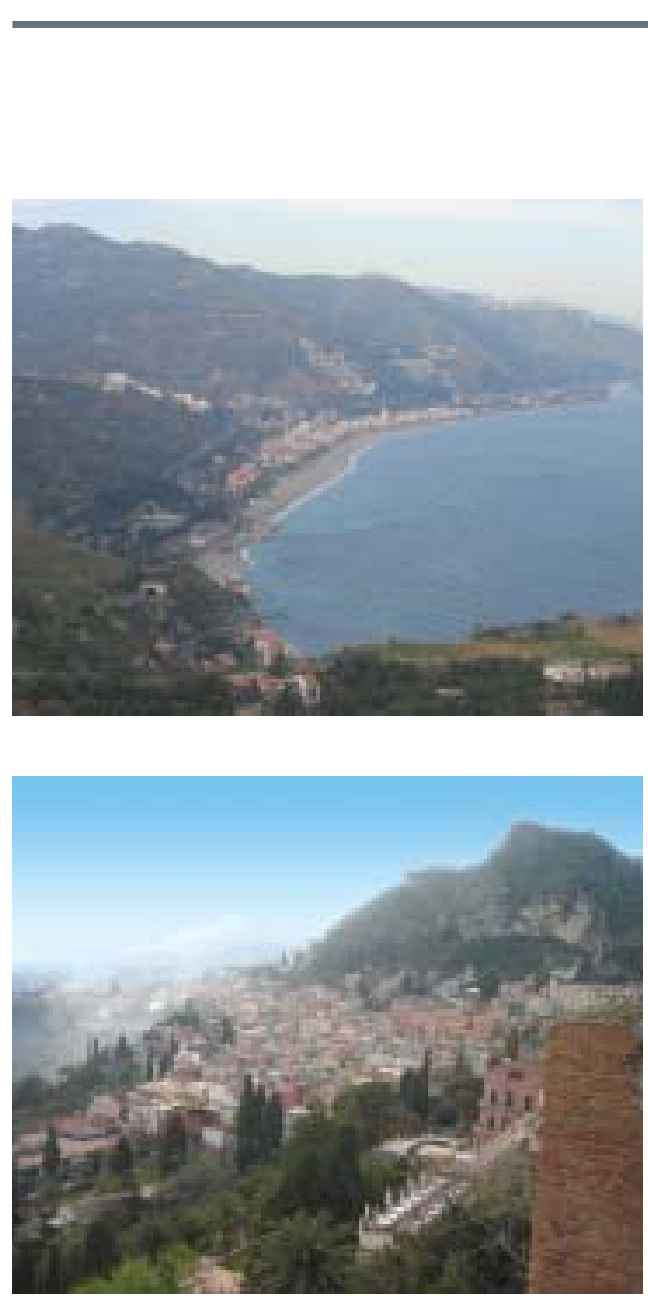

molecular engineering on the uses of stem cells in the lungs.

Highlights of the conference were, as ever, the outstanding presentations of new science, particularly by young scientists, from PhD students to post-doctoral and clinical scientists. The acceptance rate of $\sim 30 \%$ for abstracts submitted to the meeting again ensured a very high standard of presentation.

The ERS Lung Science Conference provides a unique opportunity for clinical and non-clinical scientists from different disciplines to meet and discuss basic scientific processes of common interest. The format of the meeting and the location encourages much discussion amongst scientists and many collaborations have arisen as a result of these scientific interactions.

It is hoped that the success of these meetings will influence the annual ERS congress, with an increase in the amount of basic science being presented. This will be encouraged by the suggestion to be put to the Scientific Committee that a "highlights of Taormina" symposium should be established at the ERS Annual Congress, in which the best presentations from Taormina will also appear in a symposium at the annual meeting.

Among the many supportive comments received from participants at this meeting, perhaps the best came this year, when a young post-doctoral scientist at the beginning of his presentation said "If I knew respiratory meetings were this good I'd have come much more often". The ERS is to be commended on establishing and funding these meetings, which provide a showcase for respiratory science. It is hoped they will continue to be an important feature in the ERS calendar.

The details of next series of conferences is beginning to be finalised, and a taster of what can be expected is given here.

The major topic over the next 2 years will be Hypoxia. The programme has been finalised and should be available on the website by the time you read this article. The intention of the organisers was to give more space for posters and oral presentations. The programme will run over two and a half full days, starting on Friday morning and finishing on Sunday lunchtime. As in the past, 40 bursaries will be available for young presenting authors for accepted abstracts.

\section{Lung Science Conference Taormina 2006 and 2007}

\section{Hypoxia in lung biology and disease}

Chairman: Werner Seeger, Giessen

Co-Chairman: Max Gassmann, Zurich

Scientific Committee: William MacNee, Gerhard Sybrecht, Paolo Palange, Monica Spiteri, Robert Naeije, Stephen Archer, Paul Schumacker, Marco Maggiorini, Geoff Laurent, Patrick Levy

\section{Taormina 2006 Major Topics}

I Basic mechanisms of hypoxia-sensing and oxygendependent signalling

I Oxygen-sensing and control of ventilation

I Acute lung vascular responses to hypoxia

I Hypoxia in sleep-related disorders

\section{Taormina 2007 Major Topics}

【 Hypoxia-dependent gene regulation

I Chronic lung vascular remodelling in hypoxia

I Hypoxia-driven angiogenesis

I Hypoxia in lung development and alveolar remodelling

Deadline for abstract submission for the 2006 conference is October 3, 2005. 